\title{
International Union of Microbeam Analysis Societies (IUMAS) 2014
}

\section{Established 1994}

doi:10.1017/S1431927614013208

The International Union of Microbeam Analysis Societies, founded in 1994, is a non-profit organization of professional societies whose objective is to promote world-wide cooperation in all aspects of microbeam analysis, to achieve this through the organization of an International Congress on microbeam analysis every four years, and to participate in joint committees with other scientific organizations in matters relevant to microbeam analysis which are better discussed on a world scale.

\section{IUMAS Council}

IUMAS President

IUMAS Secretary

IUMAS Past President

Australian Microbeam Analysis Society

CSIRO Australia

Canadian Microscopical Society

Canadian Federation for Development of Microscopy

Brazilian Society for Microscopy and Microanalysis

Microanalysis Society

The $141^{\text {st }}$ Committee on Microbeam Analysis, Japan

Technical Committee of Microbeam Analysis, China

Technical Committee of Microbeam Analysis, China

Korean Society of Microscopy

European Microbeam Analysis Society

European Microbeam Analysis Society
Se Ahn Song

Nicholas W.M. Ritchie

Brendan Griffin

Richard Wuhrer, President

Colin MacRae

Anja Geitmann, President

Pierre-Mathieu Charest

Sonia Bao

Edward Vicenzi

Yahichi Sato, President

Jiang Zhao

Fen Liu

Young-woon Kim

Michael B. Matthews, President

Xavier Liovet, Vice President

\section{Past Meetings}

\begin{tabular}{lll}
\hline & Location & Chair \\
2012 & Seoul, South Korea & Se Ahn Song \\
2008 & Perth, Australia & Brendan Griffith \\
2005 & Firenze, Italy & Clive Walker \\
2000 & Kona, Hawaii USA & David Williams \\
1996 & Sydney, Australia & Clive Nockolds
\end{tabular}




\section{IUMAS Early Career Scholars}

\section{At-Large ECS Winners Supported by Microbeam Analysis Society}

Aki Takigawa, Carnegie Institute of Washington

"Morphologies, Isotopes, Crystal Structures, and Microstructures of Presolar $\mathrm{Al}_{2} \mathrm{O}_{3}$ Grains: a NanoSIMS, EBSD, EDS, CL, and

FIB-TEM Study"

Shirin Kaboli, McGill University

"Electron Channeling Contrast Observations in Deformed Magnesium Alloys"

\section{Australian Microbeam Analysis Society}

Aoife McFadden, University of Adelaide South Australian Museum

"Otolith Biomineralisation: Insights From a Microstructural and Microanalytical Study"

Tim Murphy, University of Western Sydney

"Mineral Analyses \& Implications on the Dispersion of Bismuth in the Super-gene Environment of Eastern Australia"

"X-ray Mapping Investigations of the Monazites from the Mt Weld Deposit - Compositional Variance as an Indicator of Provenance"

\section{Brazilian Society for Microscopy and Microanalysis}

Vitor Hugo Balasco Serrao, Electron Microscopy Physics Institute of São Carlos, University of São Paulo

"Investigation of Escherichia coli Selenocysteine Synthase (SelA) Complex Formation Using Cryo-Electron Microscopy (Cryo-EM)"

Patricia Fernanda Andrade, Department of Chemistry, University of Campinas

"Structural and Morphological Investigations of $\beta$-Cyclodextrin-Coated Silver Nanoparticles"

\section{Canadian Society for Microscopy, Canadian Federation for Development of Microscopy}

Samuel Bastien, Chemical and Biotechnological Engineering, Universite de Sherbrook

"Plasma Synthesis of Facetted Nickel nano-Ferrites with Controlled Stoichiometry"

Xiaohui Zhu, Chemistry and Chemical Biology, McMaster University

"Probing Magnetic Polarities of Magnetotactic Bacteria by X-ray Magnetic Circular Dichroism in a Scanning Transmission

X-ray Microscope"

\section{Technical Committee of Microbeam Analysis of China}

Zhu Ruan, University of Science and Technology of China

"Quantum Monte Carlo Simulation for Atomic Resolution SEM/STEM Image"

Yanbo Zou, University of Science and Technology of China

"Model-Based Library for Critical Dimension Metrology by CD-SEM"

\section{European Microbeam Analysis Society}

Aurélien Moy, Commissariat à l'Energie Atomique, Centre de Marcoule DEN/DTEC/SGCS/LMAC

"Quantification Of Actinides By EPMA: A New Accurate Standardless Approach"

Philippe T. Pinard, RWTH Aachen Gemeinschaftslabor für Elektronenmikroskopie (GFE)

“Towards Reliable Quantification of Steel Alloys at Low Voltage"

\section{Japan - The $141^{\text {st }}$ Committee on Microbeam Analysis}

Masaru Irita, Tokyo University of Science

"A Study of Single-Walled Carbon Nanotube Cap Structure Using Field Emission Image"

Shoko Matsushita, School of Medicine, Hamamatsu University

"Volatile p-nitroaniline as Matrix for High Spatial Resolution Imaging of Phospholipids in Both Ion Modes by AP-MALDI-IMS"

\section{KSM, Korean Society of Microscopy}

Yinsheng He, School of Nano \& Advanced Materials Engineering

"Microstructural Evolution of SS304 upon Various Shot Peening Treatments"

Youngji Cho, Korea Maritime and Ocean University

"Morphology and Structure Analysis of Graphene by Low Voltage TEM" 
The Microanalysis Society is pleased to hold the Sixth Meeting of the International Union of Microbeam Analysis Societies (IUMAS) in conjunction with Microscopy \& Microanalysis 2014. All M\&M 2014 attendees are encouraged to arrive a couple of days early to participate in the exciting scientific program and social activities of IUMAS-6!

\section{IUMAS HALF-DAY WORKSHOPS}

\section{SATURDAY, AUGUST 2, 2014}

Connecticut Convention Center, Rooms 12-17

These workshops are designed to be highly interactive, with substantial exchange among the participants under the moderation of the conveners. IUMAS delegates will attend two half-day workshops, one in the morning and the other in the afternoon.

\section{8:30 AM - 12 PM}

Advanced Electron Probe Microanalysis

Paul K. Carpenter, Washington University in St. Louis, USA

Silvia Richter, Aachen University, Germany

Atom Probe Tomography

Thomas F. Kelly, Cameca Instruments, USA

François Vurpillot, Université de Rouen, France

Electron Backscatter Diffraction

Joseph R. Michael, Sandia National Laboratories, USA

Electron and X-ray Spectroscopies in the TEM/STEM

Nestor J. Zaluzec, Argonne National Laboratory, USA

$\mathrm{He} / \mathrm{Ne}$ Ion Microscopy and Microanalysis

David C. Joy, University of Tennessee and Oak Ridge

National Laboratory, USA

Quantitative X-ray Microanalysis by XEDS

Dale E. Newbury, National Institute of Standards and

Technology, USA

\section{1:30 PM - 5 PM}

Trace Element Microanalysis by Laser Ablation ICP-MS Alan Koenig, U.S. Geological Survey, USA

Focused Ion Beam Microscopy and Microanalysis Lucille A. Giannuzzi, L.A. Giannuzzi and Associates, USA Keana Scott, National Institute of Standards and Technology, USA

Microanalysis in the Variable Pressure SEM Brendan J. Griffin, The University of Western Australia

Quantitative X-ray Microanalysis by XEDS Dale E. Newbury, National Institute of Standards and Technology, USA

\section{Scanning Probe Microscopy}

Phillip E. Russell, Appalachian State University, USA

\section{Spectral Imaging and Analysis}

Nicholas C. Wilson, CSIRO-Minerals, Australia

Paul G. Kotula, Sandia National Laboratories, USA

X-ray Spectral Processing and Simulation Nicholas W. M. Ritchie, National Institute of Standards and Technology, USA

Xavier Llovet, Universitat de Barcelona, Spain

\section{SUNDAY KEYNOTE PRESENTATION 8:45 AM \\ Connecticut Convention Center, Room 15-16-17 \\ My Lab is on Mars: Geochemical Adventures with the Mars Curiosity Rover \\ Professor Laurie A. Leshin \\ Office of the President, Worcester Polytechnic Institute, USA}

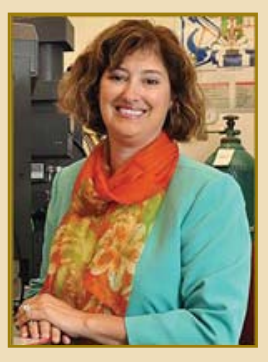

Professor Laurie Leshin is a leader in the field of cosmochemistry, with primary research interests in deciphering the record of water in objects within our solar system. Prior to her appointment as President of WPI, Prof. Leshin served as the Dean of the School of Science at Rensselaer Polytechnic Institute and the Deputy Director for Science and Technology at the NASA Goddard Space Flight Center. She is an active member of NASA's current mission, the Mars Science Laboratory. In her talk, she will share her unique perspective regarding the findings of the Mars Curiosity Rover.

\section{IUMAS PLENARY SESSION}

\section{SUNDAY, AUGUST 3, 2014}

Connecticut Convention Center - Room 15-16-17

10:30 AM Multi-spectral Electron Microprobe- Now and Future Colin M. MacRae, CSIRO-Minerals, Australia

11:10 AM Advances in Acquisition of Hyperspectral Images Paul G. Kotula, Sandia National Laboratories, USA

11:50 AM Atomic Resolution X-ray Analysis in AberrationCorrected Scanning Transmission Electron Microscopes: Current Limits and Challenges toward Quantification Masashi Watanabe, Lehigh University, USA

1:30 PM H.G.J. Moseley; The Scientist Who Put the Z in ZAF (and kab) David Williams, The Ohio State University, USA

1:50 PM Impacts of Atom Probe Tomography on the Electronic and Photonic Devise Technology Chan-Gyung Park, Pohang University of Science and Technology, Korea

2:30 PM Robert E Ogilvie: Inventor, MAS Founder, and Educator Joseph Goldstein, University of Massachusetts, USA

2:50 PM Advances in Electron Energy-Loss Spectroscopy with High Spatial and Energy Resolution Gianluigi Botton, McMaster University, Canada

4:00 PM Mass Spectrometry of Surfaces Using Ion Beam: Molecular Mapping of (Bio)Polymers Birgit Hagenhoff, tascon GmbH, Germany

4:40 PM Elemental Analysis of Cells \& Tissues Peta L. Clode, The University of Western Australia 